\title{
6 \\ What about the boys?: Sexualization, media and masculinities
}

\section{Sara Bragg}

Familiar responses to the issue of boys and sexualization lead in opposite directions. Some suggest that we really don't need to worry about them at all, as a mother in my earlier research argued: 'Well, you don't need to worry about a wee boy dressing to look older and looking tarty or anything' (Buckingham et al., 2010). Others, such as those below, suggest that we do need to worry about them (sometimes, in fact, we need to be extremely concerned indeed, as the last quotation from Bronwyn Davies implies), but in a very different way from how we worry about girls.

[G]irls are sexualised to a much greater degree than boys ... That children themselves are now being sexualised in ... ways that emphasise male domination seems likely only to increase the risk that the ethical values that foster healthy relationships will be undermined, in particular for boys. (Rush \& La Nauze, 2006: 5, 46)

The belief that girls are sexual objects may be related to boys' tendency to sexually harass girls in school and in this way could affect girls adversely (APA, 2007: 32)

Boys who are exposed to sexualised media are likely to perceive women to be sex objects. (Coy, 2009: 373)

In developing the character of Lisa they [primary school children] find it difficult to find an alternative to sexy, pretty and scared. If she cannot be these, she must be 'fat and ugly', even 'fuckin' ugly'. This aggressive description from Brian is evocative of an attitude I encountered when counselling an adolescent boy involved in gang rape... (Davies, 2003: 110)

These responses, or affects, are embodied indicators of what moves, fascinates or unsettles us; they appear spontaneous and immediate but are inevitably socially shaped. 'Follow the affect' - your feelings and visceral reactions to a topic, analysing critically where they come from - is one of Danielle Egan's very useful precepts for gaining greater insight into the sexualization debates (Egan, 2013: 136-137). I try to do this here, arguing that our affects about boys, media and sexualization might be produced in part at least by the theories or models of culture, learning and individual agency embedded in them, which also restrict and limit strategies for change. I then go on to explore how feminist media and cultural studies has long since challenged their core suppositions and thereby brought issues of masculinity and male audiences into a different kind of 
view in the sexualization debate. I draw these together with recent work on theories of social practice (Shove, 2010; Shove, Pantzar \& Watson, 2012) to suggest how we might re-conceptualize the politics of sexualization.

I will also be following my own affects: remembering my partner's nephew Jozef, then aged about 17, quipping (in a context I now cannot recall) 'bros before hos', and my response (something like amusement, immediately followed by guilt at my feminist lack). During the research on 'sexualized' goods that generated the first quotation of the chapter, many parents had told us that what they saw as such relatively trivial items weren't 'worth the battle', and indeed, I have myself argued for bringing a more benign gaze to bear on the issue (Bragg \& Buckingham, 2013). But I did so as part of opposing the anti-sexualization position's often punitive approach to (particularly, working-class) girls and their mothers and victim-blaming in relation to sexual violence. It was not intended to laugh off women's experiences, as detailed for instance on the Everyday Sexism blog (everydaysexism.com). Was finding 'bros before hos' funny part of our culture's general inability to take sexism seriously? What should I have said to Jozef? But equally, why do I worry so much about that question, as if the whole of my feminist politics hangs on getting it right?

\section{Culture and audience in anti-sexualization discourse}

The anti-sexualization position repeatedly indicts popular, commercialized culture, targeting advertisements, magazines, TV, films, music videos and consumer goods. Consider these examples:

The world is saturated by more images today than at any other time in our modern history. Behind each of these images lies a message about expectations, values and ideals. Women are revered - and rewarded - for their physical attributes and both girls and boys are under pressure to emulate polarised gender stereotypes from a younger and younger age. ... [T]hese developments are having a profound impact, particularly on girls and young women. ... [I]t is important to look at the social scripts children are being influenced by and what makes children susceptible to them.... The predominant message for boys is to be sexually dominant and to objectify the female body.... Sexualised ideals of young, thin, beauty ... [and] 'airbrushing' photographs... can lead people to believe in a reality that does not exist. (Papadopoulos, 2010: 5, 7-8, my emphasis)

A content analysis of ... Barbie Magazine [demonstrates that] fully three quarters ... is sexualising material.... [the authors] noted that the 'clear message ... is that ... a girl needs products, products, products'... that 'each issue is a large and clever advertisement which uses development and psychological knowledge to market products to young and vulnerable children'.... [particular poses] can have a sexualising effect. ... they are now being replicated by children, who have not yet developed the adult physical features such poses are calculated to show off.... For girls, examples include ... the demure pose 
(downcast eyes, which have the effect of drawing attention to the body). (Rush and la Nauze, 2006: viii \& 24 my emphasis)

Last summer, sick of the pocket money-stealing, overly sexy and ridiculously similar role models on offer in pop music, [performance artist] Bryony Kimmings and [her niece] Taylor Houchen decided to play the global Tween machine at its own game by inventing a new type of pop star ... the dinosaur-loving, bike-riding, tuna-pasta-eating Catherine Bennett ... [who] sings songs about things other than love, fame and money.

[publicity for That Catherine Bennett Show aka Credible Likeable Superstar Role Model, 2014]

Typically in the sexualization debate, as here, media are described in metaphors that suggest they are not so much a cultural expression or a language, but a form of (damaging) social action, a homogenous, negative and coercive force that 'bombards', 'saturates' and 'dominates', that is at worst invasive, 'other' and alien, at best an unavoidable but highly problematic environment, the 'wallpaper of our lives' as it is referred to in the 2011 UK government review (DfE, 2011).

Meanings are singular, not to mention simple. One 'clear' or 'predominant' message can be identified in texts, not multiple or ambiguous ones. These meanings are located in, or even more insidiously 'behind', single texts in stable ways - that is, they can be identified in isolation from their generic, narrative or viewing contexts. They are efficacious in and of themselves; that is, they alone are able to have 'effects' and to act - to 'sexualize' for instance. Identifying those meanings, and whether they are 'objectionable', falls to those with particular authority or expertise, who can also define what genres and cultural fields should (or should not) guide our interpretation. In content analysis, to which Rush and La Nauze refer, researchers predetermine a supposedly objective definition of a phenomenon and then quantify its occurrence in a sample of media. In relation to media violence, context is generally deemed irrelevant, generating the conclusion that cartoons are the 'most violent content' on television. For Rush and La Nauze, by contrast, the (only) relevant frame of reference for understanding contemporary images of children is adult media, including soft porn.

Pleasures are viewed with suspicion: Garner argues that 'spectacle' offering 'momentary ... plastic pleasures' attempt to 'mask that sexism and inequality' (Garner, 2012: 330, cited in Brodala, 2014). However, the main source of the media's threat is held to reside in the truth status and power of the information they convey. Describing texts as 'unrealistic' or offering a 'distorted' view assumes that there exists an external reality against which media can be assessed for their degree of correspondence. In turn, this holds up realism as an aesthetic ideal, suggesting that texts should 
ideally follow coherent, linear and 'probable' narratives, showing character development and moral consequences (particularly of the 'casual sex' the media are accused of promoting; one might note that 'reality' is what children ought to believe about the world, because they will act on that basis). The description of 'Catherine Bennett' suggests that such diversity and colourful character complexity (palaeontology and pasta) is largely missing from mainstream ('ridiculously similar') culture. Indeed, fantasy modalities, particularly formulaic, spectacular and excessive representations, are often deemed morally reprehensible because they 'objectify'.

Power, in these accounts, is possessed by monolithic institutions ('the global Tween machine'), and shaped by the wider economic or ideological imperatives of the capitalist system. This theory is often expressed in the pedagogical or rhetorical question of "whose interests are served by $x$ or y image?'. Effects and meanings are 'calculated' for the purpose of profiteering or 'pocket-money-stealing'. Rush and La Nauze state that 'companies invent new products and then rely on advertising to attract a market for them' (46, my emphasis), as if commodity production proceeds without reference to demand or consumers, and advertising is a mechanism that unproblematically delivers sales.

Audiences, at least in the form of undifferentiated 'children', are conceived as products of this environment, powerless ('susceptible' or 'vulnerable') victims who cannot resist the false ways of being and thinking offered by the media. The dominant metaphor of passive 'exposure' to the media, and truisms about children spending more time with screens than in schools, suggest that young people are unable to make critical sense of what they encounter. The concept of 'role models' too assumes that audiences absorb and imitate media content, responding in a literalist way to surface features such as gender. Thus girls identify with female characters, boys with male. As a consequence, the media teach them radically different lessons, especially as they grow older. Girls identify themselves with female sex objects, internalize a male gaze and ultimately are taught their submissive position in the patriarchal order. Boys, however, occupy the powerful and active male gaze directly, aligning themselves with the male heroes they are offered, learning to be dominant and even to see themselves as having an 'uncontrollable entitlement to women's always sexualized and available bodies' (Garner, 2012: 328 cited in Brodala, 2014). Girls become objects for themselves and for others; boys learn to see girls as objects whilst remaining subjects themselves.

The quotations about boys at the start of the chapter are all informed by these assumptions and equate masculinity and activity, although they view their consequences rather differently. For those who approve of - or at least don't see anything particularly wrong with - a potent male sexual subjectivity, there isn't any need to worry about boys. Their 'dressing to look older', perhaps in 
imitation of their screen heroes, is an understandable attempt to access the plenitude of a speakable (hetero)sexual identity that can be viewed with indulgence, even admiration. Others insist on the logical continuities between this and sadistic or sexist values and attitudes, with potentially dangerous consequences for girls and for male-female relationships.

These theories of media power and meaning are not new, of course; versions of them can be found in older campaigns against media violence (Bragg, 2000). They undoubtedly connect with the preoccupations of a broad spectrum of critics, particularly on the Left, with media influence and agenda-setting. They also establish templates for intervention. One option, for instance, is increased state regulation - as we have seen in the UK government's moves to make internet service providers apply a mandatory 'objectionable content' filter by the end of 2014 (Buckingham, 2014). Here, describing media as a form of social action and focusing on children might help avoid accusations of undermining freedom of speech. However, on the whole, calls for censorship tend to be muted (the government presented filtering as 'consumer choice' rather than regulation) and the banning of individual texts (such as Robin Thicke's notorious 2013 single 'Blurred Lines', by some two dozen UK university student unions) greeted with concern rather than celebration.

It is more common to hear recommendations that are pedagogic in nature - involving the circulation of 'positive' images and programmes of 'media literacy'. Alternative 'role models' or media content will instil their audiences with new attitudes, values and beliefs, as the Credible Likeable Superstar Role Model title suggests. Media literacy tends to be conceived as teaching children to be 'critical' viewers, who resist the machinations of media interest behind the dazzling seductive images. Linda Papadopoulos, for instance, argues that it will enable children to 'filter out unhealthy messages' and 'reduce the negative impacts of exposure' (2010: 34, 36). This is education of a very limited - although familiar - kind: an inoculation against media influence, even a kind of protective sunscreen (Bragg \& Buckingham, 2013; Buckingham, 2003). At times the insistence that it can be administered by the otherwise untrained becomes laughable, as when mothers are encouraged to spend 'two minutes' showing their daughters how images are airbrushed in order to teach them 'not to try and live up to an image of perfection that doesn't exist' (in Bragg, 2012). In a more sophisticated and developed account, Davies (2003) describes working with a female researcher, Chas, and groups of Australian primary school children to raise their awareness of the 'constitutive force' of gender representations in popular media and fairy tales. Children are taught about the 'dominant discourse' of male/female dualism, learn to 'disrupt the familiar patterns of gender relations' and create alternative storylines that also open up a 'different kind of agency' (201). 
Such strategies for change operate within a dominant psychological paradigm that emphasizes the significance of human behaviour, and intervenes at this individual level. Elizabeth Shove and colleagues have highlighted its inadequacy in relation to climate change. Shove shows (2010) how current policy-making is predicated on an 'ABC' model in which social change is said to depend on values and attitudes (A), which drive the kinds of behaviour (B) that individuals 'choose' to adopt (C). Analyses of sexualization frame the problem similarly: wrong (sexist) attitudes and beliefs lead to wrong actions. Thus in the quotations at the start of the chapter, Rush and La Nauze assume that behaviours such as 'healthy relationships' rest on 'values' that are 'undermined' by media misconceptions about male domination, and the APA asserts that boys' belief that girls are sexual objects may explain their actions towards (harassment of) girls. Change attitudes and beliefs (either by changing the media content that shapes them, or directly by pedagogical strategies), and behaviours will change - as will, ultimately, society.

Shove contends that such framing both obscures the role of institutions including governments in perpetuating unsustainable practices, and 'marginalises and excludes serious engagement with other possible analyses included those grounded in social theories of practice' (2010: 1274). Her arguments help explain why it comes to be seen as so important that individuals do not appear to express sexist 'attitudes' (because these are considered to be external drivers that shape their behaviours); whilst also, perhaps, illuminating why such monitoring seems so inadequate as a response to the scale of the issues.

It is worth lingering a while on the 'mode of address' of the pedagogies mentioned above that is, who they think young people are, who they want them to be and what ways of 'reading' the world they construct for them (Ellsworth, 1997). While apparently benign and liberal, they leave little space for young people's perspectives (unlike, say, Renold, 2013). In the sexualization literature, children are occasionally cited if their views align with campaigners' and policy-makers'. For instance, Papadopoulos cites uncritically a girl reflecting that 'I've started worrying a lot more about my weight and body image. That could be caused by all the magazines I read in a week' (59); Davies reports the claims of some (white, middle-class) girls to have been enlightened and 'amazed' by Chas. However, when children resist such adult 'ventriloquism', their views are discounted, used as evidence of how they have been deceived and misled, or worse. Papadopoulos argues that "while children themselves may believe that they can understand and contextualise, say, a Playboy logo on a pencil case ... such encounters may be having a profound impact on attitudes and behaviour at an unconscious level' (29, my emphasis). Davies's gloss on 'Brian' is even more judgemental. In the exchange on which the quotation at the start of the chapter is based, Chas asks a group of (working-class and aboriginal) children to develop the character of a 'woman victim' in 
their story in a way that is 'completely different' from the 'dominant discourse' of 'sexy and pretty'. This is why Anna proposes 'fat and ugly' (but this is merely a logical reversal of the terms) and Brian's 'fuckin' ugly' then plays on and twists her words. Both suggestions, that is, are responses to how the teacher addressed and positioned them in the first place, and while Brian does mobilize sexist discourse, this does not necessarily indicate a commitment to an oppressive world order beyond the classroom. To read a pun - the return of a sound that is almost but not quite 'fat and ugly' - by a ten or 11-year-old boy as suggesting that he is like a rapist is psychologically crude. This is not to condone Brian's remark; but it is to suggest the importance of examining the disciplinary power relations of critical pedagogies and media literacies.

Feminist scholars have repeatedly returned to 'Girl Number 20', a metaphor for the problem of classroom strategies that encourage critique of gendered subjectivities, but which, by assuming that the subject position of autonomous, distanced viewer is equally available to all, often have the effect of silencing (particular) girls' voices (Williamson, 1981/1982; Turnbull, 1998; Gonick, 2007). In relation to working-class boys and young men, I would argue that often the psychodynamics of the encounter with 'otherness' (Bhabha, 1994) meshes with what Pearson (1983), in his study of 'hooligans', terms the history of 'respectable fears'. When those 'others' do not echo adults' own words, but instead respond in ways that displace and challenge adults' identities as imparters of knowledge and truth, (middle-class) adults tend to find in their words menace and aggression (cf. Young, 1990: 47; see also Bragg, 2000).

\section{Media and audience in feminist and cultural studies}

Cultural and feminist studies approaches have long challenged the kinds of assumptions about culture and agency made in arguments about media violence as well as sexualization. The necessarily schematic account below indicates briefly how this work insists on the ambiguity and complexity of popular cultural texts; considers pleasure to be potentially radical rather than/as well as problematic; views audiences as active; and insists on the performativity of textual analysis and method.

Rather than a form of social action, as above, media texts are taken to be a language or form of cultural expression, whose meanings are necessarily ambiguous and open-ended. Popularity is taken to indicate not successful manipulation of a gullible audience, but that a text resonates with the contemporary moment: thus the relevant question is not one about effects, but about the nature of the society in which these media make sense. Intertextual approaches move beyond the analysis of single texts as self-contained objects, to their accompanying texts and practices, such as the 
star/celebrity system, publicity, censorship, exhibition and reviewing (Mayne, 1993). These are seen as actively working to fragment and pluralize the text in order to maximize its audience and to create 'divergent' readings (Klinger, 1989: 7). They therefore dispute that mainstream commercial products have limited polysemy compared to 'open' alternative or avant-garde texts (or, to put it another way: Taylor Swift is at least as interesting as 'Catherine Bennett'). Tony Bennett's concept of 'reading formation' explains how meaning is 'activated' by readers according to the cultural sources available to them (Bennett, 1983: 7), displacing the privilege granted to academic interpretations whilst noting that different institutions (schools, the press, etc.) may 'superintend' readings in particular ways. The notion of distorted or inaccurate readings or texts thereby becomes irrelevant: meaning and impact derive from texts' relation to other texts rather than to an external reality, while any interpretation is valid if we aim to explore how it came about, rather than to evaluate its truth.

Lumby and Albury's (2010) response to Rush and La Nauze is a contemporary example of contextualized arguments about meaning. They survey contemporary Australian girls' popular culture and representational traditions, from media to family photography, arguing that set in this broader context rather than against earlier soft porn, the kinds of poses and clothing Rush and La Nauze condemn are in fact commonplace, and this alters the 'cultural messages' they can be said to carry (145). While they try to limit interpretation by referring to the gaze of 'reasonable adults', I like Simpson (2011) have argued that acknowledging ambiguity may allow us to tolerate the anxiety of thinking about childhood sexuality in terms of both agency and abuse, without one excluding the other, which may open new possibilities for conceptualizing children's sexuality (Bragg, 2014).

Cultural studies perspectives identify realism as one historically specific set of generic conventions with no automatic superiority. They consider the pleasures of 'low' cultural forms and re-evaluate the question of fantasy. As Linda Williams remarks, circular and repetitive narratives, improbability, lack of psychological depth, infantile emotions and spectacular excesses are 'moot as evaluation points if such features are intrinsic to their engagement with fantasy' (1991: 9). Pleasures have been perceived as a potential source of alternative political imaginings (Dyer, 1977); as that which can move us and deliver the unexpected (Mercer, 1986), and thus provide a basis for disruption rather than stabilization of meaning. Psychoanalytically informed work has drawn (for instance) on Laplanche and Pontalis (1986 (1964)) to see cinema as the mise en scène or setting of desire - one in which the subject is 'caught up in the sequence of images', rather than in pursuit of a definite object or content. 
Audiences have generally been seen as active meaning-makers rather than passive receivers or cultural dupes, not least because the latter view is politically paralysing. As such, the media act as resources - essential, constitutive elements in our capacities to make sense of the world, 'tools to think with' about self and other, for making sense of cultural space and identity, in specific contexts (e.g. Buckingham \& Sefton-Green, 1994; Silverstone, 1994, 1999). Empirical studies of audiences emphasize the varied meanings and uses they make of texts, often against expectations. For instance, in relation to video games such as Grand Theft Auto, some young players prove uninterested in their most controversial features, such as murderous 'mission structures' and misogynist 'hacks' (DeVane \& Squire, 2008), while others use them in ways that connect to their own life experiences of violence (Renold, 2013); elsewhere young people refuse to define their online sexual experimentation as victimization (Brodala, 2014). Studies also emphasize social context: the processural, domestic and everyday nature of media reception, for example, challenges claims about effects that attempt to separate texts from the far broader patterns of social interactions in which they are embedded (Morley, 1986). Fan studies commonly stress the 'insider knowledge' of conventions acquired by seasoned audiences, which enables them to read and play with the different levels of meaning in the text. At its most sophisticated, this literature interprets gender and other social categories, not as stable a priori variables generating different interpretations, but instead as the historically and culturally specific effect of technologies of subjectivity, such as viewing practices and indeed research methods (Harbord, 2002).

Feminist media scholarship from the 1980s onwards increasingly described genres, forms and fantasies as gendered - referring partly to textual processes (narrative structure, for example), but also to the significance of a sexed audience for, and sexed authorship of, particular cultural forms. Initially many feminist critics ignored 'male' genres, instead focusing on women's forms such as magazines, soap opera and romantic fiction (Ang, 1985; Radway, 1987; Winship, 1987; Geraghty, 1991). Their aim was to redeem their aesthetic, moral and other qualities from the disparagement commonly targeted at them and by extension their audience; and in the process to instantiate new understandings of femininity.

However, this criticism also arguably involved a polarizing construction of the feminine and the masculine. For instance, analyses of soap opera stressed the open and process-centred nature of its narratives, which were also argued to be qualities of 'feminine desire'. But in order to do this, masculine desire (as in crime fiction or classic Hollywood narrative) had to be constructed as closed, goal-centred and so on. 'Thus a fit is established between the narrative patterns, the thematic content of these shows, particular qualities associated with masculinity/femininity, and finally, male and female viewers' (Tasker, 1991: 89). In the process, there is a slippage between notions of sex 
(of the audience, or characters) and gender (as a subject position or set of cultural competences). The ignoring of men as audiences for 'women's genres' tended to fix 'the feminine' with women, and crucially, notions of identification were considerably simplified in order to sustain the argument.

Subsequent work, notably 'bad girl' feminism and queer theory, rejected visions of women as inherently nurturing and paid increasing attention to 'nonconformist' media consumption by women and 'male' popular cultural genres such as action, horror and pornography. One particularly influential example is the work of Carol Clover on horror, in Men, Women and Chainsaws (1992). Her work is most appropriately read as a contribution to the psychoanalytically informed debate about the gendered cinematic gaze that Laura Mulvey had initiated in 1975 (Mulvey, 1989). Clover challenges key aspects of psychoanalytic film theory, especially its assumption of a sadistic male spectator identifying with a star of the same gender. In an argument with much resonance for contemporary debates about sexualization, she calls this a 'status-quo supportive cliché of modern cultural criticism' that has not served 'real life women and feminist politics' well (1992: 226). She explores the textual processes that force an identification between young male audience members and female characters, especially the masochistic (victim-identified) or passive viewing positions the films set up. Highlighting the instability and fluidity of masculine identities, aligning male audiences with an unstable rather than a powerful gaze, aims to forge new political alliances. She even reads young male audiences' preparedness to identify with female victims as a promising 'visible adjustment in the terms of gender representations' (127). Such work challenges mimeticism and insists on the fluidity of spectatorial identifications.

Subsequent work has been even more radical in, for instance, exploring the pleasures of violent fantasy for women (Hart, 1994) and the 'queering' of spectator positioning through the monstrous 'reconfiguring' of gender in more recent horror films, such as Texas Chainsaw Massacre 2 (Halberstam, 1995). Meanwhile Penley's analysis of the homoerotic 'slash fiction' produced by heterosexual women fans of Star Trek showed that fantasies can be written across the bodies of male characters. Although they do not represent women or call themselves 'feminists', imagining Kirk and Spock as both heterosexual and homosexual means the women can identify with - be them as phallic and powerful, but at the same time still have them as sexual objects, since as heterosexual they are still available to them (Penley, 1992). The demand for a broader range of representations to be made available in popular culture is important politically, but Penley's work challenges the idea that only then can they be useful for audiences. Walkerdine's work on the meanings of Rocky was an early (and still rare) example of an analysis that allows a mainstream film to serve metaphorical functions for a white working-class man (Walkerdine, 1986). 
Textual analysis of these kinds can be seen as a 'performative act' or 'active intervention in meaning-making' that does not 'discover' pre-existing meanings in texts, but enacts creative interpretations with the potential to bring new meanings, identities and possibilities into being - and indeed to close down others. In relation to sexualization, Duschinsky observes the inconsistency with which images of women are described as 'hypersexualized', but equivalent images of men merely 'hypermasculinized', reinforcing the gender-specific effects ascribed to girls versus boys (Duschinsky, 2013). In general the complacent assumption that men adopt only the 'masterful' position as viewers enacts masculine subjectivity in specific and limited ways, as I note below.

These perspectives relate to Shove's in their displacing of individual human agency as the driver of change. In Judith Butler's more Foucauldian and discourse-oriented account, human subjects are conceptualized as 'interpellated kinds of being, dependent on ... a language we never made in order to acquire a tentative ontological status' (Butler, 1997: 26). She emphasises the ambivalence of our 'linguistic vulnerability', our reliance on meanings that we borrow but cannot control. Subjectivity is performatively enacted rather than pregiven; and agency derives from within language rather than from without. In this sense it 'sustains as well as threatens' (27), Butler argues, not in its content, but through the address that brings us into being and thereby gives us the possibility of both speaking (agency) and answering back (resistance). Our responsibility lies in our 'repetition' rather than 'origination' of language, for what meanings we sustain or challenge when we use it (ibid.). But this is more a question of context (time, place and audience) than intention. If some speech acts can be unhappy or infelicitous, then none are necessarily efficacious as hate speech theory - or, here, anti-sexualization discourse - suppose. Taking up Derrida's work on the inevitable iterability of language, Butler argues that each new utterance performs a 'break' with context that allows for reinscription and misappropriation rather than simple reproduction of meanings (Butler, 1997: 147). In effect she argues for the strategy of resistance that Bronwyn Davies uses - although Davies might not recognize it as such. Davies cites Brian's pun, breaking with the context in which it was uttered, giving it a new meaning by placing it in her feminist academic textbook and relating it to the words of a rapist. Similarly, by re-citing it myself I hope to have again shifted how we read it.

We might consider this also in relation to 'Blurred Lines'. The controversy around this hit song centred on both the video (which, directed by a woman, in its 'unexpurgated' form showed topless women with the three fully clothed male performers), and the violent and non-consensual overtones of lyrics such as 'you know you want it' and 'I'll give you something big enough to split your ass in two'. The public debate interestingly demonstrated the reach of (feminist-inflected) 'media literacy' skills, considering for instance whether the women gazing directly into the camera 
rather than adopting the conventional 'eyes-down demure' pose (described by Rush \& La Nauze, above) represented their 'empowerment' or their availability to the male gaze. Describing it as 'objectionable', however, calls to mind Butler's suggestion that 'hate speech' theory might be displacing fears about how all language 'injures' us by disallowing our fantasies of 'radical autonomy' and self-creation. The video is certainly seductive: I find myself desirous, 'caught up in the sequence of images', wanting both to be and to have the beautiful women. The idea that boys and men watching the video would only ever identify with the subject position of 'having' the woman as object, never with 'being' themselves sexually passive, in my view says far more about our culture's homophobia than about masculine fantasy. While the video's playful tone should not allow it to avoid responsibility for its meanings, censorship seems to me less relevant than the many subsequent feminist parodies of the video that appeared online. Geraldine Harris, reviewing these, notes how the 'feminist blogosphere' has helped reinvigorate feminist debate, whilst the web in general simultaneously accommodates proliferating misogynistic sites and practices such as trolling or 'slut-shaming'. As she argues, the web 'provides a fascinating contemporary example of Michel Foucault's analysis of the complexity of the relationship between power and resistance' (Harris, 2014). It cannot easily be said to be the location of either empowerment or oppression. Nonetheless, the parodies represent an ethical manoeuvre, exploiting fault lines and aporia in representations in order to return meaning in a different form; in so doing, they promote reflection and resistance within the discourses and practices of everyday life, rather than relying on a gesture of censorship or critique delivered from above. The kind of politics and pedagogy my arguments envisage here are not a brief stop to hand over our adult tools of reason and knowledge about texts or institutions to arm children against influence, but an ongoing struggle, focused more on 'social selfunderstanding' (Richards, 1998) and on 'reflecting back a difference that makes a difference' (Ellsworth, 1997) to give young people new relationships to what they 'already' know.

There is further room to connect these arguments to social theories of practice, which similarly displace attention away from individuals to consider how practices persist or decline, how they 'recruit' individuals to carry them and how individuals might 'defect' (Shove et al., 2012). One example is that of 'lad culture' in universities, which the 'Blurred Lines' controversy served to highlight. While there are continuities with earlier practices of masculine competitiveness and harassment, Alison Phipps argues that lad culture needs to be set in the context of the commodification of higher education in the UK and the aggressively individualistic and consumerist practices that this promotes (Phipps \& Young, 2014). Likewise, we might read the growth of sex industry work in the light of austerity policies that have disproportionately affected 
women's public sector employment and education opportunities (or, as a protester against student fees expressed it eloquently on her placard: 'ok, I'll be a stripper then').

\section{Conclusion}

In general the postmodern perspectives on which I have drawn in the second part of this chapter involve giving up on certainty. And this, of course, is difficult, because it involves not knowing what someone or something means, whether an image is positive or negative, what the effect of our well-intentioned pedagogical and campaigning efforts will be; accepting that we may not liberate, empower, deliver critical audiences, or oblige young people to abandon their fascination with the media. It means being reflexive about the performative impact of our textual analyses and our constructions of gendered audiences, about the power relations of pedagogical addresses that vainly seek only to hear our own words reflected back to us.

On the other hand, it doesn't mean giving up on any of these either. Interrupting dominant discourses about the male sex drive or girls and women 'asking for it', challenging everyday sexism and demanding resources for survivors of sexual abuse and violence are all still as important and necessary as ever. Some of our critical categories and concepts, our analyses and reflections, will offer useful resources for young people, help them think about themselves and society in new and radical ways; but - so too will the media themselves. And perhaps we need to be more ambitious in identifying what elements of sexist practices might be disrupted, how to force discontinuities and defections, rather than monitoring individuals.

So finally, back to 'bros before hos'. When I asked Jozef if I could cite it, he responded 'Hearing that feels like seeing a Facebook photo from years ago and seeing a terrible haircut and wondering why it ever happened.' The comparison to a haircut seems apposite, in the light of my comments above about the 'triviality' of the objects that are so often the focus of anti-sexualization campaigners' energies. But now I can be clearer about what taking a statement like 'bros before hos' seriously (or not) might involve. It is not trivial or insignificant. There is much to say about what it encodes: a rich history of relations and borrowings between black and white, urban and suburban youth cultures, a repressed-in-plain-view homoeroticism/homosociality, for example. It is also witty, poetic, vivid. More locally, I was intrigued by its capacity to shed a different light on Jozef's more visible identity at that time, at least in the family contexts where I encountered him, as a pro-Tory, church-going teenager. All this is interesting, in my view. But what we cannot do is to peer through language into Jozef's originating intention; we cannot say once and for all what it means and what it tells us about him, his attitudes, values or beliefs. He, like all of us, is constituted 
in language but not determined by it; we cannot predict his future, as Davies threatens to do for Brian. Thus it is important to me that in this chapter I have also cited Jozef's final-year undergraduate paper on sexualization (Brodala, 2014). His journey to writing it showed me that young people, men as well as women, are not as lost as we seem to fear; that they may find their way through the maze of contemporary culture - with or without input from the inadequately feminist adults around them.

\section{References}

Ang, I. (1985) Watching Dallas: Soap opera and the melodramatic imagination D. Couling (Trans.). London and New York: Methuen.

APA (2007) Report of the American psychological association task force on the Sexualization of

Girls. Washington, DC: American Psychological Association. Retrieved 04042011, from http://www.apa.org/pi/women/programs/girls/report.aspx.

Bennett, T. (1983) 'Texts, Readers, Reading Formations' Bulletin of the Midwest Modern Language Association 16 (1): 3-17

Bhabha, H. K. (1994) The location of culture. London and New York: Routledge.

Bragg, S. (2000) Media violence and education: A study of youth audiences and the horror genre. Unpublished PhD. London: Institute of Education University of London.

Bragg, S. (2012) What I heard about sexualisation: or, conversations with my inner Barbie. Gender and Education, 24 (3), 311-316.

Bragg, S. (2014) 'Shameless mums' and universal pedophiles: The sexualization and commodification of children, in C. Carter, L. Steiner, \& L. McLaughlin (Eds.) The Routledge Companion to Media and Gender. London and New York: Routledge 321-331.

Bragg, S., \& Buckingham, D. (2013) Global concerns, local negotiations and moral selves: Contemporary parenting and the 'sexualisation of childhood' debate. Feminist Media Studies, 13 (4), 643-659. doi: 10.1080/14680777.2012.700523. 
Brodala, J. (2014) How do young people experience sexualisation based on their gender? How has the rise of instant messaging services, in particular MSN impacted on these differences?. Political Science BA (Hons), University of Birmingham, Unpublished undergraduate dissertation.

Buckingham, D. (2003) Media education: Literacy, learning and contemporary culture.

Cambridge: Polity.

Buckingham, D. (2014) Objectionable content? Young people, censorship and pornography. Unpublished. Retrieved from https://http://www.academia.edu/7453955/Objectionable_content_Young_people_censorship_and_ pornography.

Buckingham, D., Bragg, S., Russell, R., \& Willett, R. (2010) Sexualised goods aimed at children: A report to the Scottish parliament equal opportunities committee. Glasgow: Scottish Parliament.

Clover, C. (1992) Men, women and chainsaws: Gender in the modern horror film. London: British Film Institute.

Buckingham, D., and Sefton-Green, J. (1994) Cultural Studies Goes to School, London and Bristol, PA: Taylor and Francis Ltd

Butler, J. (1997) Excitable Speech: A Politics of the Performative, London and New York: Routledge

Coy, M. (2009) Milkshakes, lady lumps and growing up to want boobies: How the sexualisation of popular culture limits girls' horizons. Child Abuse Review, 18 (6), 372-383. doi: 10.1002/car.1094. Davies, B. (2003) Shards of glass: Children reading and writing beyond gendered identities. NSW, Australia: Hampton Press.

DeVane, B., \& Squire, K. D. (2008) The meaning of race and violence in Grand Theft Auto San Andreas. Games and Culture, 3 (3-4), 264-285. 
DfE (2011) Letting children be children: Report of an independent review of the commercialisation and sexualisation of childhood. London: Department for Education.

Duschinsky, R. (2013) Sexualization: A state of injury. Theory \& Psychology, 23 (3), 351-370.

Dyer, R. (1977) Entertainment and Utopia. Movie, 24, 2-13.

Egan, R. D. (2013) Becoming sexual: A critical appraisal of the sexualization of girls. Cambridge: Polity Press.

Ellsworth, E. (1997) Teaching positions:Ddifference, pedagogy and the power of address. New York: Teachers College Press.

Garner, M. (2012) The missing link: The sexualisation of culture and men. Gender and Education, 24 (3), 325-331. doi: 10.1080/09540253.2012.670392.

Geraghty, C. (1991) Women and soap opera: A study of prime time soaps. Cambridge: Polity Press. Gonick, M. (2007) Girl number 20 revisited: Feminist literacies in new hard times. Gender \& Education, 19 (4), 433-454. doi: 10.1080/09540250701442625.

Halberstam, J. (1995) Skin shows: Gothic horror and the technology of monsters. Durham, NC, and London: Duke University Press.

Harbord, J. (2002) Film cultures. London: Sage.

Harris, G. (2014) Parodying 'blurred lines' in the feminist blogosphere. Contemporary Theatre. Retrieved from http://www.contemporarytheatrereview.org/2014/parodying-blurred-lines/.

Hart, L. (1994) Fatal women: Lesbian sexuality and the mark of aggression. Princeton, NJ: Princeton University Press.

Klinger, B. (1989) 'Digressions at the Cinema: reception and mass culture' Cinema Journal 28 (4): 3-19

Laplanche, J., \& Pontalis, J.-B. (1986 (1964)) Fantasy and the origins of sexuality, in V. Burgin, J. Donald, \& C. Kaplan (Eds.) Formations of Fantasy. London: Methuen 5-27 
Lumby, C., \& Albury, K. (2010) Too much? too young? The sexualisation of children debate in Australia. Media International Australia, 135, 141-152

Mayne, J. (1993) Cinema and Spectatorship, London and New York: Routledge

Morley, D. (1986) Family television: Cultural power and domestic leisure. London: Comedia.

Mulvey, L. (1989) Visual and other pleasures. Basingstoke and London: Macmillan.

Papadopoulos, L. (2010) Sexualisation of young people review. London: Department for Education and Employment.

Pearson, G. (1983) Hooligan: A history of respectable fears. London and Basingstoke: Macmillan.

Penley, C. (1992) 'Feminism, Psychoanalysis, and the study of Popular Culture'. In Cultural Studies, ed. L. Grossberg, C. Nelson, and P. Treichler (479-400), New York and London: Routledge

Phipps, A., \& Young, I. (2015) Neoliberalisation and 'lad cultures' in higher education. Sociology.Vol. 49(2) 305-32 doi: 10.1177/0038038514542120.

Radway, J. A. (1987) Reading the romance: Women, patriarchy and popular literature (British edition ed.). London and New York: Verso.

Renold, E. (2013) Boys and girls speak out: A qualitative study of children's gender and sexual cultures (age 10-12). Cardiff: Cardiff University.

Richards, C. (1998) Teen spirits: Music and identity in media education. London and Bristol, PA: UCL Press.

Rush, E., \& La Nauze, A. (2006) Corporate paedophilia: Sexualisation of children in Australia, working paper no. 90. Canberra: ACT: Australia Institute. Retrieved from http://www.tai.org.au/documents/dp_fulltext/DP90.pdf. 
Shove, E. (2010) Beyond the ABC: Climate change policy and theories of social change.

Environment and Planning. A, 42 (6), 1273.

Shove, E., Pantzar, M., \& Watson, M. (2012) The dynamics of social practice: Everyday life and how it changes. London: Sage.

Silverstone, R. (1994) Television and Everyday Life, London and New York: Routledge

Silverstone, R. (1999) Why Study the Media?, London, Thousand Oaks, New Delhi: Sage

Simpson, B. (2011) Sexualizing the child: The strange case of Bill Henson, his 'absolutely

revolting' images and the law of childhood innocence. Sexualities, 14 (3), 290-311. doi:

$10.1177 / 1363460711400809$.

Tasker, Y. (1991) Having It All: Feminism and the pleasures of the popular, in S. Franklin, C. Lury, \& J. Stacey (Eds.) Off-Centre: Feminism and Cultural Studies. London: Harper Collins Academic $85-96$

Turnbull, S. (1998) Dealing with feeling: Why girl number twenty still doesn't answer, in D.

Buckingham (Ed.) Teaching popular culture: Beyond radical pedagogy. London and Bristol, PA:

UCL Press 88-106.

Walkerdine, V. (1986) 'Video replay: families, films and fantasy'. In Formations of Fantasy, ed. V. Burgin, J. Donald, and C. Kaplan (167-199), London: Routledge

Williamson, J. (1981/1982) How does girl number 20 understand ideology? Screen Education, 40(Autumn/Winter), 80-87.

Winship, J. (1987) Inside women's magazines. London: Pandora.

Young, R. (1990) White mythologies: Writing history and the west. London and New York:

Routledge. 